\title{
PENGARUH PELATIHAN TERHADAP KOMPETENSI PEDAGOGIK GURU MATEMATIKA
}

\author{
Loviga Denny Pratama ${ }^{1}$, Wahyu Lestari ${ }^{2}$ \\ ${ }^{1}$ Tadris Matematika, Institut Ilmu Keislaman Zainul Hasan, Indonesia \\ Email penulis pertama: loviga.pratama@gmail.com
}

\begin{abstract}
The purpose of this study is to test the influence of teacher's training on pedagogical competence (especially aspects of knowledge and skills). This study was a survey research with the entire population of junior and senior high school mathematics teachers. The research sample were 20 randomly selected teachers from 7 junior high school teachers and 13 senior high school teachers on 3 different areas in Indonesia. The data collected by tests and non-test will analyzed with statistical techniques and inferensial (Anava). The results showed that teacher's training effective in pedagogical competence especially aspects of skill. However, this training has no effect on aspects of knowledge. Furthermore, that makes no effect and what training is needed by teachers of mathematics will also be discussed in this article. In addition, this findings can be used as a reference by schools in the choose the type of training required to improve the pedagogical competence.
\end{abstract}

Keywords: pedagogical competence; teacher's training; mathematics teacher

\begin{abstract}
Abstrak
Penelitian ini bertujuan untuk menguji pengaruh pelatihan pada pedagogik guru matematika (aspek pengetahuan dan keterampilan). Penelitian ini merupakan penelitian survei terbatas dengan populasi guru matematika SMP dan SMA. Sampel penelitian ini sebanyak 20 guru yang dipilih secara acak dari 7 SMP dan 13 SMA yang tersebar di 3 daerah yang berbeda di Indonesia, yaitu Kota Probolinggo, Kabupaten Probolinggo, dan Kabupaten Jember. Data dikumpulkan dengan teknik tes dan non tes serta dianalisis dengan teknik statistik dan inferensial (Anava). Hasil penelitian menunjukkan bahwa pelatihan yang diikuti guru selama ini berpengaruh pada kompetensi pedagogik guru dalam aspek keterampilan. Namun, pelatihan ini tidak berpengaruh pada aspek pengetahuan. Adapun hal-hal yang membuat tidak berpengaruh serta pelatihan apa saja yang diperlukan oleh guru matematika juga akan dibahas pada artikel ini. Sehingga hasil penelitian ini dapat dijadikan rujukan oleh lembaga sekolah dalam memilih jenis pelatihan yang diperlukan untuk meningkatkan kompetensi pedagogik guru matematika.
\end{abstract}

Kata kunci: Kompetensi Pedagogik; Pelatihan guru; Guru matematika

Guru sebagai pendidik tentunya berpengaruh terhadap proses pembelajaran serta memiliki peran besar dalam pencapaian tujuan pendidikan. Faktanya, guru memiliki kontribusi dalam menentukan keberhasilan siswa. Adapun kemampuan kognitif dan afektif yang dimiliki guru akan memengaruhi $65 \%$ keberhasilan siswa dan jika didukung dengan pembelajaran yang berkualitas maka interaksi tersebut akan bermanfaat hingga 90\% (Heijden, Geldens, Beijaard, \& Popeijus, 2015). Dalam hal ini, guru juga memengaruhi prestasi siswa (Lestari, Pratama, \& Jailani, 2018; McCormack, Gore, $\&$ Thomas, 2006). Selain itu, untuk melatih siswa yang siap bersaing di era modern, mereka harus dididik oleh guru yang memiliki kapasitas dan kompetensi yang memadai sesuai dengan kebutuhan masa depan. Oleh karena itu, di era sekarang ini guru perlu meningkatkan pengetahuan dan keterampilan mereka untuk meningkatkan dan mengeksplorasi praktik mengajar mereka (Parker, 2018).

Dalam rangka implementasi guru dalam mengajar, kompetensi guru menjadi hal yang perlu dipertimbangkan dan dibahas secara mendalam (Selvi, 2010). Kompetensi guru memengaruhi nilai, perilaku, komunikasi, tujuan, dan praktik mengajar mereka (Parker, 2018). Dalam hal ini, kompetensi dapat dibahas dalam banyak dimensi seperti kompetensi lapangan, kompetensi penelitian, kompetensi 
kurikulum, kompetensi pembelajaran seumur hidup, kompetensi sosial budaya, kompetensi emosional, kompetensi komunikasi dan teknologi informasi, dan kompetensi komunikasi (Selvi, 2010). Di Indonesia, kompetensi guru meliputi kompetensi pedagogik, kompetensi kepribadian, kompetensi sosial, dan kompetensi profesional (Undang-Undang RI, 2005). Sehingga pada penelitian ini dibatasi pada kompetensi pedagogik guru matematika.

Berbagai upaya harus dilakukan untuk meningkatkan kompetensi guru termasuk kompetensi pedagogik. Seberapa baik guru dalam mengajar tergantung pada motivasi, kualifikasi, pengalaman, pelatihan, bakat dan faktor-faktor lain (Kazu \& Erten, 2016). Kompetensi guru juga tergantung pada pelatihan mereka ikuti (Shukla, 2014). Guru harus terus belajar, mengikuti kegiatan ilmiah seperti pelatihan, seminar, lokakarya untuk memperluas wawasan, meningkatkan pengalaman dan menerapkannya dalam kegiatan belajar mengajar yang dilakukan oleh guru (Wenno, 2016). Sehingga salah satu yang terpenting dalam meningkatkan kompetensi yakni guru perlu mengikuti kegiatan pelatihan. Melalui pelatihan dapat mempengaruhi profesionalisme guru dalam mengar (Lyles, 2015). Pelatihan antar guru dapat bertukar masalah beserta penyelesaiannya tentang kegiatan pembelajaran, serta sarana dan prasaran dalam kegiatan pembelajaran. Misalnya di era Industri 4.0 ini, pengadaan pelatihan tentang penggunaan teknologi sangat diperlukan agar guru dapat secara efektif menggunakan aplikasi teknologi dalam pembelajaran. Tentunya hal-hal seperti ini dapat meningkatkan kualitas guru dalam mengajar.

Saat ini di berbagai dunia memperbarui sistem pendidikan dengan mengatur pelatihan guru secara ketat untuk mendapatkan tingkat profesionalisme yang lebih tinggi (OECD, 2016). Oleh karena itu, tantangan baru bagi guru sekarang ini diperlukan adanya pelatihan sehingga dapat terfokus dalam meningkatkan profesionalisme mereka. Pelatihan ini mencakup berbagai kegiatan yang harus diikuti guru selama periode tertentu, sebagai bagian dari pengembangan profesionalme guru (Lyles, 2015).Dalam hal ini, tampaknya pelatihan memiliki peran penting bagi profesionalisme guru. Oleh karena itu pada penelitian ini akan mengidentifikasi pengaruh pelatihan yang diikuti oleh guru matematika terhadap kompetensi pedagogik mereka. Sejalan dengan tujuan tersebut, pertanyaan penelitian diformulasikan sebagai berikut:

1) Apakah pelatihan memengaruhi kompetensi pedagogik guru matematika dalam aspek pengetahuan?

2) Apakah pelatihan memengaruhi kompetensi pedagogik guru matematika dalam aspek keterampilan?

\section{METODE}

Metode yang digunakan dalam penelitian ini adalah metode survei terbatas. Metode ini digunakan karena tujuan penelitian ini adalah untuk mengetahui apakah pelatihan memengaruhi kompetensi pedagogik baik dari aspek pengetahuan maupun aspek keterampilan dalam sampel terbatas. Adapun Subjek dalam penelitian ini adalah sampel terbatas yang dianggap cukup mewakili populasi 
guru SMP dan SMA. Sampelnya menggunakan 20 guru yang dipilih secara acak dari 7 SMP dan 13 SMA dengan pengalaman mengajar 1-6 tahun. Subjek penelitian tersebar di 3 daerah yang berbeda di Indonesia, yaitu Kota Probolinggo, Kabupaten Probolinggo, dan Kabupaten Jember. Pemilihan sampel didasarkan pada kemudahan akses penelitian dan keterbatasan waktu peneliti.

Instrumen penelitian ini terdiri dari tes dan angket. Instrumen tes digunakan untuk mengukur kompetensi pedagogik guru dari aspek pengetahuan. Sedangkan instrument angket digunakan untuk mengukur kompetensi pedagogik guru dari aspek keterampilan. Selain itu, angket juga digunakan untuk mengukur pelatihan terkait yang telah diikuti oleh guru. Selanjutnya, penelitihan ini akan menjawab pertanyaan penelitian tentang pengaruh pelatihan terhadap kompetensi pedagogik guru matematika dalam aspek pengetahuan dan aspek keterampilan. Adapun estimasi koefisien Alpha Cronbach masingmasing pada tes, angket pedagogik guru, dan angket pelatihan guru sebesar $0.81 ; 0.86$; dan 0.79 .

Tes pilihan ganda digunakan untuk mengukur kompetensi pedagogik guru matematika dalam aspek pengetahuan yang terdiri dari 10 poin dengan masing-masing dibagi menjadi 2 pertanyaan berkaitan dengan prinsip-prinsip pembelajaran, metode pembelajaran, prinsip-prinsip pengembangan kurikulum, teknik penilaian, dan karakteristik siswa. Angket dikembangkan melalui 51 pernyataan kompetensi pedagogik guru matematika khususnya pada aspek keterampilan. Adapun inti dari pernyataan angket ini menjurus pada pernyataan tentang kemampuan guru dalam mengelola pembelajaran, penerapan metode pembelajaran, komunikasi guru, pemahaman karakteristik siswa, penggunaan sumber belajar, dan pemanfaatan teknologi. Adapun skala pengukuran yang digunakan dalam angket ini menggunakan skala Likert.

Dalam mengumpulkan informasi terkait pelatihan yang diikuti oleh para guru, angket dikembangkan dalam 15 item pernyataan dengan masing-masing dibagi menjadi 5 pernyataan berkaitan tentang pelatihan kurikulum, metode pembelajaran, dan media pembelajaran berbasis teknologi. Adapun skala pengukuran yang digunakan dalam angket ini juga menggunakan skala Likert. Selain itu, peneliti juga memberikan pertanyaan terbuka kepada subjek tentang jenis dan karakteristik pelatihan yang dibutuhkan oleh guru matematika dan pertanyaan tentang kesesuaian pelatihan yang mereka ikuti dengan kebutuhan mereka.

\section{HASIL}

Data yang diperoleh dalam penelitian ini akan dianalisis melalui statistika inferensial menggunakan regresi linier. Nantinya analisis ini kan menjawab pertanyaan penelitian yang sudah dijelaskan di atas. Berikut akan diasajikan deskripsi hasil pengumpulan data pada penelitian ini. 


\section{Tabel 1.}

Signifikansi Antara Pelatihan dan Aspek Pengetahuan Guru

\begin{tabular}{clccccc}
\hline & Model & Jumlah Kuadrat & Df & $\begin{array}{c}\text { Rata-rata } \\
\text { Kuadrat }\end{array}$ & F & Sig. \\
\hline \multirow{2}{*}{1} & Regresi & 3,425 & 1 & 3,425 & 0,513 & $0,513^{\text {b }}$ \\
& Residual & 131,813 & 18 & 6,225 & & \\
& Total & 135,000 & 19 & & & \\
\hline
\end{tabular}

Tabel 1 menunjukkan bahwa $\mathrm{F}$ hitung $=0,492$ dengan nilai $\mathrm{p}>0,05$. Nilai ini menunjukkan bahwa tidak ada pengaruh yang signifikan antara pelatihan dan kompetensi pedagogik guru dalam aspek pengetahuan. Selanjutnya, kami akan membahas kemungkinan penyebab terjadinya kondisi ini. Berdasarkan pertanyaan yang diberikan dalam angket terkait dengan pelatihan yang diikuti oleh guru, diperloeh hasil persentase pada Gambar 1.

Pertanyaan: Apakah pelatihan yang Anda dapatkan sesuai dengan kebutuhan Anda dalam meningkatkan kompetensi pedagogik Anda?

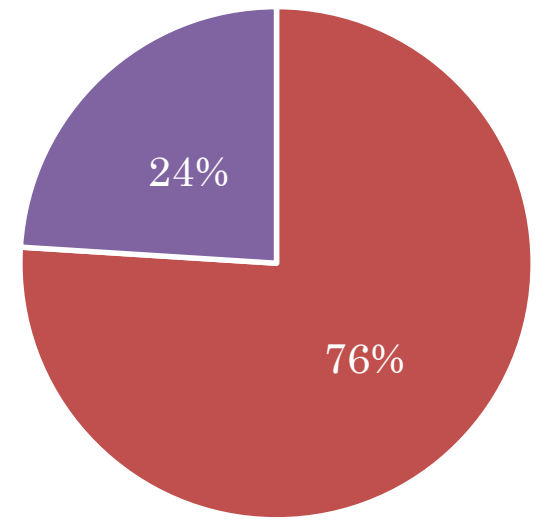

\section{- Belum Mewakili - Sudah Mewakili}

\section{Gambar 1. Pertanyaan Terkait Kebutuhan Pelatihan Guru}

Gambar 1 menunjukkan pelatihan yang selama ini mereka ikuti belum mewakili kebutuhan seorang guru dalam meningkatkan kompetensi pedagogik mereka. Hal ini dapat menjadi salah satu faktor yang menyebabkan pelatihan tidak secara signifikan memengaruhi kompetensi pedagogik guru matematika dalam aspek pengetahuan. Tentu hal ini sangat disayangkan, mengingat pentingnya kesesuaian pelatihan yang mereka ikuti dalam menunjang pedagogik guru. Melalui pengetahuan pedagogik yang baik akan berpengaruh pada pemahaman dalam pengajaran yang berkualitas (Rose, 2018), sehingga akan memberikan dampak pada hasil belajar siswa (Kiel, Lerche, Kollmannsberger, Oubaid, \& Weiss, 2016)

Selain itu, ada beberapa alasan mengapa pelatihan tidak dapat mewakili kebutuhan guru dalam meningkatkan kompetensi pedagogik mereka dalam aspek pengetahuan. Setidaknya ada 4 penyebab 
yang ditemukan yakni: pelatihan lebih fokus pada praktik sehingga jarang membahas teori kompetensi pedagogik guru (36,3\%); pelatihan dilakukan dalam waktu yang singkat $(28,7 \%)$; pelatihan tidak berkelanjutan (20,4\%); pelatihan difokuskan pada media pembelajaran (14,6\%).

Hal-hal yang disebutkan di atas (terutama tentang teori kompetensi pedagogik yang jarang dibahas) dapat menjadi alasan mengapa kompetensi pedagogik guru ditinjau dari aspek pengetahuan tidak dipengaruhi oleh pelatihan yang mereka ikuti. Pelatihan yang selama ini mereka ikuti juga juga tidak adanya tindak lanjut antar sesama peserta pelatihan. Padahal tindak lanjut dalam sebuah pelatihan guru sangat diperlukan untuk dapat mengimplementasikan teori-teori yang meraka dapat saat pelatihan. Selain itu, keberlanjutan dalam sebuah pengaplikasian teori yang didapatkan saat pelatihan dapat menjadi investasi terbesar seorang guru dalam melakukan pembelajaran (Khumaedi, Sunyoto, \& Nugroho, 2017).

Tabel 2.

Signifikansi Antara Pelatihan dan Aspek Keterampilan Guru

\begin{tabular}{lccccc}
\hline Model & Jumlah Kuadrat & df & $\begin{array}{c}\text { Rata-Rata } \\
\text { Kuadrat }\end{array}$ & F & Sig. \\
\hline Regresi & 717,989 & 1 & 717,989 & 6,231 & $0,022^{\text {b }}$ \\
Residual & 2074,211 & 18 & 115,234 & & \\
Total & 2792,200 & 19 & & & \\
\hline
\end{tabular}

\section{Pertanyaan: Apakah Anda membutuhkan pelatihan yang terus menerus dan komunikatif antar sesama peserta pelatihan bahkan ketika waktu pelatihan sudah berakhir?}

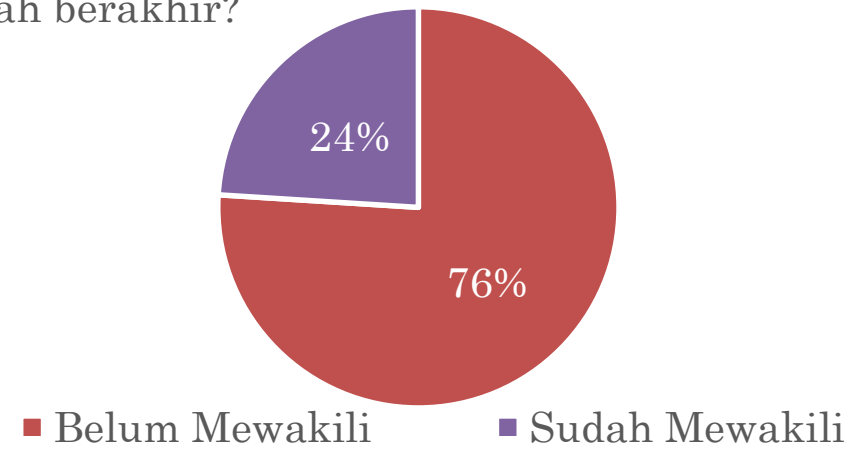

Gambar 2. Pertanyaan Terkait Karakteristik Pelatihan yang Diperlukan

Selanjutnya, Tabel 2 pada aspek keterampilan guru, ditemukan bahwa F hitung = 6,231 dan nilai $\mathrm{p}<0,05$. Nilai ini menunjukkan ada pengaruh yang signifikan antara pelatihan dan kompetensi pedagogik dalam aspek ketrampilan. Adapun pelatihan yang menurut mereka berpengaruh kuat yakni pada pelatihan media teknologi. Memang dalam menghadapi era Industri 4.0 guru sangat memerlukan adanya suatu keterampilan penggunaan teknologi dalam proses pembelajaran. Mengingat pada penelitian sebelumnya (Pratama \& Setyaningrum, 2018; Pratama, Bahauddin, \& Lestari, 2019; Setyaningrum, Pratama, \& Ali, 2018) ditemukan bahwa penggunaan teknologi dapat membantu dan 
memfasilitasi siswa dalam memahami konsep pembelajaran. Sehingga dalam hal ini penggunaan teknologi di bidang pendidikan harus benar-benar diperhatikan oleh guru matematika. Bahkan dalam pembelajaran matematika pun, telah banyak diterapkan berbagai media (Saputro \& Ratu, 2018) bahkan aplikasi (Aini \& Ayu, 2019) yang dapat digunakan dalam pembelajaran matematika.

Di sisi lain, berdasarkan Gambar 2 terkait pelatihan yang diikuti oleh guru, sebagian besar mereka merasakan perlunya pelatihan yang berkelanjutan dan komunikatif antar sesama peserta pelatihan sehingga pelatihan yang diadakan tidak hanya dalam bentuk lokakarya yang akan berakhir dalam hitungan hari. Selain itu, juga ditemukan bahwa guru matematika sangat membutuhkan pelatihan terkait instrument, metode, dan media pembelajaran. Padahal dalam sebuah proses pembelajaran, ketiga hal tersebut menjadi komponen yang wajib dipertimbangkan di setiap pertemuaannya (Budiningsih, 2011). Sehingga dari penemuan penelitian ini, diharapkan dapat ditindaklanjuti oleh para praktisi di bidang pendidikan.

\section{KESIMPULAN}

Berdasarkan penelitian ini, membahas kompetensi pedagogik guru pada aspek pengetahuan dan keterampulan. Ditemukan bahwa kompetensi pedagogik guru matematika dilihat dari aspek pengetahuan tidak dipengaruhi oleh pelatihan guru. Namun, lain halnya dengan aspek keterampilan dimana sangat dipengaruhi oleh pelatihan guru. Selain itu, guru matematika membutuhkan pelatihan berkelanjutan dan komunikatif dengan jenis pelatihan dalam bentuk alat pelatihan instrumen pembelajaran, metode pembelajaran, penggunaan teknologi informasi, dan media pembelajaran.

Adapun temuan penelitian ini merekomendasikan lembaga sekolah agar memperhatikan kebutuhan masing-masing guru sebelum melakukan pelatihan. Termasuk juga pada jenis pelatihan yang diperlukan oleh guru karena pelatihan yang tepat akan sangat membantu guru matematika untuk meningkatkan kompetensi pedagogik mereka dari aspek keterampilan.

\section{DAFTAR PUSTAKA}

Aini, O., \& Ayu, K. C. (2019). Pengembangan Game Puzzle Sebagai Edugame Berbasis Android Untuk Meningkatkan Kemampuan Berpikir Matematika Siswa SD. Jurnal Teori Dan Aplikasi Matematika (JTAM), 3(1), 74-79.

Budiningsih, C. A. (2011). Karakteristik siswa sebagai pijakan dalam penelitian dan metode pembelajaran. Jurnal Cakrawala Pendidikan, 1(1).

Heijden, V. D. H., Geldens, J. J. M., Beijaard, D., \& Popeijus, H. L. (2015). Characteristics of teachers as change agents. Teachers and Teaching: Theory and Practice, 21(6), 681-699. https://doi.org/10.1080/13540602.2015.1044328

Kazu, İ. Y., \& Erten, P. (2016). Teachers' lifelong learning competencies . Elementary Education 
Online, 15(3), 838-854. https://doi.org/10.17051/io.2016.07530

Khumaedi, M. ., Sunyoto, S. ., \& Nugroho, A. (2017). Pelatihan Analisis Statistika Penelitian Eksperimen Tiga Perlakuan bagi Guru GURU SMK di Kota Semarang. Jurnal Penerapan Teknologi Dan Pembelajaran, 14(2), 135-144.

Kiel, E., Lerche, T., Kollmannsberger, M., Oubaid, V., \& Weiss, S. (2016). The Pedagogic Signature of the Teaching Profession. Journal of Education and Learning, 5(4), 201. https://doi.org/10.5539/jel.v5n4p201

Lestari, W., Pratama, L. D., \& Jailani, J. (2018). Implementasi Pendekatan Saintifik Setting Kooperatif Tipe STAD Terhadap Motivasi Belajar Dan Prestasi Belajar Matematika. AKSIOMA : Jurnal Matematika Dan Pendidikan Matematika, 9(1), 29-36. Retrieved from http://journal.upgris.ac.id/index.php/aksioma/article/view/2332/1969

Lyles, R. (2015). Teachers and Professionalism. The Clearing House: A Journal of Educational Strategies, Issues and Ideas, 30(9), 548-550. https://doi.org/10.1080/00098655.1956.11476490

McCormack, A., Gore, J., \& Thomas, K. (2006). Early career teacher profesional learning. Asia-Pacific Journal of Teacher Education, 34(1), 95-113. https://doi.org/10.1080/13598660500480282

OECD. (2016). Supporting teacher professionalism: Insights from TALIS 2013, TALIS. OECD Paris.

Parker, L. (2018). Teacher Competencies or Certification Competencies. Behavioral Disorders, 5(3), 163-168. https://doi.org/10.1177/019874298000500307

Pratama, L. D., Bahauddin, A., \& Lestari, W. (2019). Game Edukasi: apakah membuat belajar lebih menarik? At- Ta'lim, 5(1), 39-50.

Pratama, L. D., \& Setyaningrum, W. (2018). Game-Based Learning: The effects on student cognitive and affective aspects. Journal of Physics: Conference Series, 1097(1). https://doi.org/10.1088/1742-6596/1097/1/012123

Rose, D. (2018). Pedagogic register analysis: mapping choices in teaching and learning. Functional Linguistics, 5(1). https://doi.org/10.1186/s40554-018-0053-0

Saputro, T. A., \& Ratu, N. (2018). Pengembangan Media Pembelajaran Mengunakan Aplikasi Construct 2 Pada Materi Aljabar Kelas VII. Jurnal Teori Dan Aplikasi Matematika (JTAM), 2(1), $1-8$.

Selvi, K. (2010). Teachers' Competencies. Cultura International Journal of Philosophy of Culture and Axiology, 7(1), 167-175. https://doi.org/10.5840/cultura20107133

Setyaningrum, W., Pratama, L. D., \& Ali, M. B. (2018). Game-Based Learning in Problem Solving Method: The Effects on Students' Achievement. International Journal on Emerging Mathematics Education, 2(2), 157. https://doi.org/10.12928/ijeme.v2i2.10564

Shukla, S. (2014). Teaching Competency, Professional Commitment and Job Satisfaction-A Study of Primary School Teachers. IOSR Journal of Research \& Method in Education (IOSRJRME), 4(3), 44-64. https://doi.org/10.9790/7388-04324464

Undang-Undang RI. Undang-undang Republik Indonesia Nomor 14 Tahun 2005 tentang Guru dan 
Dosen. , Produk Hukum § (2005).

Wenno, I. (2016). Analysis of Factors Affecting Teacher Competence Physics Science SMP in the District of West Seram Maluku Province. International Journal of Science and Research (IJSR), 5(6), 1061-1067. https://doi.org/10.21275/v5i6.nov164349 